Applied Management Journal

2019, Vol. 20, pp.19-37

\title{
Novel Job Scheduling Tool for University Technology Transfer
}

\author{
Clovia Hamilton ${ }^{1}$ \\ Winthrop University \\ Executive Summary
}

Technology commercialization managers are often faced with (1) training inventors on intellectual property (IP) laws and IP policies, (2) evaluating invention disclosures for patentability and marketability, (3) drafting and implementing invention marketing plans, and (4) working closely with patent counsel on patent prosecution. This study begins with the fact that expediency is important because the amount of time taken to evaluate invention disclosures and file patent applications often conflicts with inventors' desire to publish their findings. Yet, very few technology transfer managers use project management job scheduling tools to minimize processing time. Next, this study describes the development of a novel job scheduling tool for university technology transfer using simulated annealing in $\mathrm{R}$ programming. A description of experimentation follows and the test results follow. Next, the discussion provides that the primary implication for technology managers is that the tasks involved in technology transfer can be scheduled quite easily and speedily with this proposed job scheduling tool. A limitation to the study is that a hypothetical set of TTO staff job tasks was scheduled. Also, faculty inventors' tasks are not included. Thus, future research should include further experimentation in actual university technology transfer offices using the job tasks that their specialists need to schedule in real time.

\footnotetext{
${ }^{1}$ This is part of Dr. Clovia Hamilton's doctoral dissertation research. She would like to thank the members of her dissertation committee for guiding her in this research: Dr. Xueping Li, Dr. Andrew Yu, Dr. James Simonton and Dr. Ernest Brothers of the University of Tennessee.
} 
Keywords: technology transfer, management of innovation, management of new technologies, project and R\&D management, $R \& D$ management, management of scientists and engineers

Technology transfer is the process of evaluating an invention disclosure for patentability and marketability, obtaining and maintaining patent protection, marketing the technology to industry, and securing licensing deals in order to generate royalty income. Technology transfer is a subset of tech management. Technology commercialization project managers are responsible for leading and directing technology transfer specialists in specific project job tasks. Thus, job scheduling software should be of interest to technology managers since it can support the management of labor, even workload distribution, and help managers plan ahead. Job scheduling allows for labor resource allocation to ensure that work is given to staff at a pace that will not overload total resource capabilities.

Although it is imperative for tech managers to reduce processing delays, it is not commonplace for university tech managers to view the tech transfer process as having individual projects with job tasks. Currently, very few university technology transfer managers use job scheduling tools. They operate in triage mode and are not as concerned with the day-to-day details of job scheduling. Yet they should be. Job scheduling can alleviate tensions between anxious inventors and technology transfer office (TTO) staff. Thus, this research study was focused on the development of a novel job scheduling tool using simulated annealing which would reach optimized scheduling fast, be easy to use and cost effective. The managerial relevance of using such as job scheduling tool in university technology transfer is that it will allow tech managers to plan clearly what their team members should accomplish and when so that they can accomplish their goals. It would reduce processing delays that frustrate faculty researchers and academic entrepreneurs who are seeking to disseminate their research findings or to gain firstmover advantage.

Well-established university TTOs experience job task processing delays (Baldini, 2008; Bercovitz, 2003; Cao, 2009; Colwell, 2002; Feldman, 2008; HBCU Innovation and Entrepreneurship Collaborative, 2014; Kenney, 2009; Markman, 2005). Despite these delays, these TTOs still earn licensing revenues. As a supply chain network, university technology transfer involves changes in patent supplies and demands for patent licenses from customers. The best value supply chains are agile and able to act swiftly in response to supply and demand changes (Ketchen, 2008). Significant delays in the TTOs' evaluation of faculty researchers' invention disclosures can thwart opportunities for faculty researchers to publish their research 
findings. In order to avoid publication delays, the literature review revealed that faculty may not submit their invention disclosures at all (Bercovitz, 2003; Cao, 2009). Once the word gets out that there are delays caused by the TTO, the word spreads among faculty quickly and this can have devastating effects on the invention disclosure rates (Tahvanainen, 2008).

The sentiment in the technology transfer profession is that technology transfer occurs best in a flexible office that does not crack under pressure and offers employees work autonomy (Bozeman \& Coker, 1992). The closest that the profession has come with respect to measuring technology transfer effectiveness is to measure outputs of what goes out the door (i.e., patent applications, licensing agreement, business formations; Bozeman et al., 2015) rather than timeliness. So, job task scheduling is not commonplace in university TTOs.

In 2009, Spivey et al. advocated that an alliance score card be used to improve established roles and responsibilities and to identify misplacements or disconnects between core competencies, value propositions for customers, and technology commercialization conventions. Although delivery delays were mentioned, there was no mention of the importance of job scheduling other than advocating honoring a commitment to keep on schedule (Spivey, 2009). The lack of use of job scheduling in technology transfer may be due to the fact that commercially available job scheduling software tools may be perceived as too hard and time-consuming to learn and use since job scheduling can be complex, difficult and time-consuming (Bahouth, 2014). Thus, there is a need for a simple and easy to use job scheduling tool that TTOs can use.

The development of the proposed Novel Job Scheduling Tool for University Technology Transfer serves to help combat the problem of technology transfer task processing delays faced by TTOs. Advanced optimization is a technique used more and more in industrial engineering; and in other science and engineering fields. It is proposed that advanced optimization can be used to provide a very simple tool to schedule technology transfer job tasks. With advanced optimization and process understanding, the technology transfer process can be efficient and repeatable (Schmidt, 2011).

\section{Method}

Herein, the following four steps in developing this proposed Novel Job Scheduling Tool for University Technology Transfer are described and they include the following elements:

1. development of a list of TTO job tasks to schedule; 
2. development of a job scheduling algorithm with the use of simulated annealing;

3. experimentation; and

4. comparison of a job schedule created with a commercially available software program to the newly developed simulated annealing job scheduling tool.

The first step was the development of a list of TTO job tasks to schedule. A literature review was used to create a university technology transfer process flow and to identify typical TTO job tasks that need to be scheduled. The number of TTO full time equivalents (FTEs) identified in the benchmarking tool was used for the TTO staff size. Since $72 \%$ of the TTOs have three (3) or fewer FTE staff members (Swamidass, 2009), an experiment was designed to schedule job tasks for 3 staff persons. Figure 1 illustrates the university technology transfer process flow. This process flow identifies the following university technology transfer job tasks which are typically conducted by TTO staff the:

- delivery of training seminars,

- evaluation of invention disclosures;

- review of outside patent counsel's patent prosecution documentation; and

- creation of marketing plans.

The second step was the development of a job scheduling algorithm using Simulated Annealing. Simulated annealing simulates the annealing process of metals in metallurgy whereby metals are annealed to make them easier to work with and bend. When a metal is annealed, it is heated up to above its critical temperature until it is red hot and glows. Then the metal is slowly cooled. The annealing heat treatment restores or increases the ductility of metal, softens it, removes residual internal stresses and makes the metal more workable. In the annealing of metals, perfect crystals are formed once a minimum energy is reached because the carbon precipitates out and this results in a coarse pearlite structure with excess ferrite (Totten, 2006, pp. 286, 334, 351).

Simulated annealing is an optimization technique based on this crystallization process. In a simulation of this annealing process, a computer algorithm begins with a first initial solution which gets modified. The algorithm continuously creates solutions which are accepted for the next iteration with a certain probability. The probability depends on a parameter called "temperature" just as in real annealing process (Kurbel, 2016). With each iteration, the temperature is reduced. Since cooling down slowly increases the computing time, a trade-off between solution quality and computing time has to be made. Simulated annealing is an ideal technique 
because this heuristic approach can be used to find optimal solutions at a low computational cost (Hedjazi, 2015; Ohsaki, 2016). Heuristic scheduling has been studied and advocated since the late 1970s (Kanet, 1991). When applied to detailed scheduling, simulated annealing performs well (Kurbel, 2016).

Simulated annealing has been proven to be able to find the global optimum solution within the entire domain of a function, rather than just a local optimum solution (Goffe, 1994). Benefits of simulated annealing include:

1. it can process functions that possess "arbitrary degrees of nonlinearities, discontinuities, and stochasticity;

2. it can process quite arbitrary boundary conditions and constraints imposed on these functions;

3. it is easy to implement with a degree of coding quite minimal relative to other nonlinear optimization algorithms, and

4. it can statistically guarantee finding an optimal solution" (Ingber, 1993).

Therefore, simulated annealing is a promising direct metaheuristic approach to reaching acceptable solutions to general scheduling problems (Bahouth, 2014).

A control flow of the algorithm is provided in Figure 2 and the variables are listed in Table 1. This simulated annealing control flow is motivated by instructions provided in Zapfel et al.'s metaheuristic search concepts (Zapfel, 2010, p. 118). The goal is to minimize job delays in university technology transfer with an advanced optimization job scheduling tool. The objective function $\mathrm{h}(\mathrm{x})$ has a "domain" which is basically the collection of all possible values that have an outcome. Here, the domain is all possible combinations of job assignments. The objective is to find the $\mathrm{x}$ for which $\mathrm{h}(\mathrm{x})$ has an optimal value by minimizing the squared difference between the amount of time a person has to work and the 8 hours they should work:

$$
\mathrm{Z}=\Sigma \quad\left(\frac{\text { dur.per.pers }}{8 h r s}\right)^{2}
$$

The goal of the algorithm is to find that point $\mathrm{x}$ in the domain for which $\mathrm{h}(\mathrm{x})$ has the maximum value. The classical approach is to (1) take an initial combination and calculate $\mathrm{h}(\mathrm{x})$; then (2) take a set of neighboring combinations (for example by switching a single job) and calculate $\mathrm{h}(\mathrm{x})$ for those. This is known as "hill climbing" because one starts somewhere on the function $h$ and just climbs up to higher regions. Still, at a local maximum, the algorithm will stop there and never reach the global maximum. The simulated annealing algorithm takes care of that problem by allowing the algorithm to jump back to "worse" states sometimes and move from there. This procedure results 
in the algorithm going to a completely different spot on the h-graph where it starts climbing again. That way the algorithm has a higher chance of arriving at or close to the global maximum.

However, there is a drawback. If the algorithm is allowed always to jump back to worse states, it might keep on jumping around and never reach any maximum at all. So, in the beginning, the algorithm is allowed to jump basically anywhere. However, it is restricted further and further. This is the "temperature" in the annealing process which is a measure of how much "worse" a state can be to be accepted. The "worse" state is not allowed to be selected. It is merely given a certain chance to be selected. This step is typically depicted as a probability rho $=\exp ($ delta h/temp). The "cooling down" of the temperature just makes it less and less likely for a worse state to be selected.

In the algorithm, two things are tracked: (1) the best solution so far, and (2) the current solution so far. The objective function is calculated. If the solution is better or slightly worse, the new solution is taken as the current state. Otherwise, the state is kept as is. If there is a switch to the new solution as the current state, a check is made on whether there is a new best solution.

This procedure allows two things: (1) the best solution improves the whole time from the start state, and (2) it can also become a worse solution. This worse solution is then the start for a new iteration and allows the algorithm to explore options farther away from the current best solution.

The third step was experimentation. The problem scenario is that three (3) TTO staff persons should work 8 hours each $=24$ hours total. Yet what if there are 26 hours of work? Also, if the team cannot work 24 hours, then the mean duration per person has to minimized. With simulation, the goal was to minimize the absolute value of deviation between completion time and due date. Table 2 (see Appendix) provides 11 hypothetical job tasks, estimated completion times, and deadlines for the three (3) TTO staff persons to complete.

The meta-heuristic method of simulated annealing was used carried out using R programming. Here are the assumptions:

- All 11 jobs are available at time $t=0$. This was assumed to be the work start time on December 1, 2015. The jobs can be carried out independently, each by one person.

- Completion times of jobs $\mathrm{i}$ are denoted by $\mathrm{C}_{\mathrm{i}}$, $\mathrm{i}=1 \ldots 11$ and the corresponding due times by $\mathrm{D}_{\mathrm{i}}$, $\mathrm{i}=1 \ldots 11$. The due times are the days until deadlines multiplied by 8 hours work per day.

- The objective function to minimize is the total number of delays.

Journal of Applied Management, Vol. 20, 2019 


$$
\mathrm{Z}=\sum_{1}^{11} \quad\left(0, \frac{C_{i}-D_{i}}{\left|C_{i}-D_{i}\right|}\right)
$$

- An alternative objective function is the total idle time. This is defined as the sum of the times each supplier waits after he/she finishes, until all jobs have been completed.

- To account for varying speeds of the TTO staff persons (i.e. suppliers), if $t_{1}, t_{2} \ldots t_{11}$ are the processing times required by Supplier \#1 for the 11 jobs, the processing times for Person \#2 are $2 t_{1}, 2 t_{2}, \ldots, 2 t_{11}$ and the ones for Supplier $\# 3$ are $3 t_{1}, 3 t_{2}$, $\ldots, 3 \mathrm{t}_{11}$.

The fourth step was the comparison of the job schedule using a commercially available Excel solver tool to the newly developed simulated annealing tool. Finally, the advanced optimization job scheduling tool based on simulated annealing was compared to a commercially available Excel Solver job scheduling tool.

\section{Results}

The total duration for each TTO staff person's job task was computed. From a coarse grain approach, it was assumed that they should all work eight (8) hours. In the experiment, the goal was to minimize the squared difference between the amount every person has to work, and the eight (8) hours they should work optimally. But in the more general case, when there are fewer than 24 hours, the algorithm can minimize to the mean duration per person.

Recall that the simulated annealing algorithm continuously creates solutions which are accepted for the next iteration with a certain probability. The probability depends on the temperature just as in the real annealing process. Thus, using the simulated annealing algorithm, a runif command in $\mathrm{R}$ programming was used to get a random probability between 0 and 1 . This was multiplied by the current temperature. This is the amount of "disturbance" or the measure of the likelihood that a worse solution is selected. The $\mathrm{h}$ value sequence plot of the sequence of states is shown in Figure 3 and the decrease in disturbance in shown in Figure 4 with the $x$ axis showing the number of iterations and the $y$ axis representing the temperatures. It is not very obvious after 1,000 iterations, but it is visible as shown in Figure 4.

The results successfully showed that all of the workers work exactly eight (8) hours and some jobs are simply not carried out. The technology transfer office manager can gain notice of which jobs are not or cannot be carried out. With this tool, the convergence of both the standard deviation and the mean for either of the candidate distributions is monitored (See Figure 5). The proposed candidate distributions are independent of the state of the chain at any given 
time. This Metropolis Hastings (MH) algorithm converges quickly and provides a solution instantly.

This optimization calculation minimizes the total delay and produces the technology transfer job schedule. The allocation of jobs to the TTO staff persons is generated in a model solution list called $\bmod \$$ sol.list with vectors. The start and end times for the jobs are generated in the vector mod\$all.times with values. Person 1 starts with job 10 which starts at $\mathrm{t}=0$ and ends at $\mathrm{t}=2$; then Person 1 continues with job 1 which starts at $\mathrm{t}=2$ and ends at $\mathrm{t}=6$; the Person 1 continues with job 7 which starts at $\mathrm{t}=6$ and ends at $\mathrm{t}=7$; and so forth for Persons 2 and 3. These jobs were manually put into Microsoft Excel. Figure 5 shows the Gantt chart that was generated.

For the purpose of comparing use of the proposed simulated annealing job scheduling tool to a commercially available tool, TTO job scheduling was conducted using a Microsoft Excel Solver template by Edwin Straver of Frontline Systems (Straver, 2001). Worker speed was not taken into consideration in the experiment. Also, instead of minimizing payroll cost, the objective was to minimize the difference in the due time and completion time (DTCT). (see Figures 3-6)

Since the TTO only has 3 employees, the 11 technology transfer jobs were split between 3 TTO employees. Although some jobs were assigned to the TTO employees, the Excel Solver could not find a feasible solution for which all of the constraints could be satisfied. Jobs 7-10 did not get assigned. Therefore, in comparison to the use of Excel Solver, the meta-heuristic simulated annealing program converged to an optimal solution that satisfied the constraints. The Excel Solver personnel scheduling tool by Straver did not find a feasible solution and did not schedule all of the jobs to all three TTO staff persons. The use of simulated annealing for job scheduling statistically guarantees finding an optimal solution (Ingber, 1993).

\section{Discussion}

The job scheduling tool experimentation illustrates how advanced optimization can be used to schedule TTO staff job tasks in a very quick and simple manner.

\section{Implications for Management}

Technology transfer is the process of evaluating an invention disclosure for patentability and marketability; obtaining and maintaining patent protection; marketing the technology to industry; and securing licensing deals in order to generate royalty income. Technology transfer is a subset of tech management. Although it is imperative for technology managers to reduce processing delays, it is not commonplace for university tech managers to view the tech

Journal of Applied Management, Vol. 20, 2019 
transfer process as having individual projects with job tasks. Very few university technology transfer managers use job scheduling tools. This research resulted in the development of a novel job scheduling tool using simulated annealing. This job scheduling tool would be easy to use and cost effective. The managerial relevance of using such as job scheduling tool in university technology transfer is that it will allow tech managers to plan clearly what their team members should accomplish and when so that they can accomplish their goals in a very simple manner. It would reduce processing delays that frustrate faculty researchers and academic entrepreneurs who are seeking to disseminate their research findings or to gain first-mover advantage.

\section{Limitations}

The theory of distribution management is a system dynamics idea applied to production distribution (Forrester, 1961, pp. 119, 128; Forrester, 1993, pp. 199-240). The supply chain management of the steps required to move products or services from the suppliers to customers is required in production distribution management. Technology transfer can be viewed as a supply chain network (Hamilton, 2016; Hamilton, 2017a; Hamilton, 2017b). However, the development of the job scheduling tool is limited to the scheduling of the TTO staff and not the entire supply chain. This limitation is due to control issues. For example, the scheduling does not consider tasks upstream of the TTO staff job tasks such as the amount of time that a faculty member takes to review documentation sent to the TTO by outside patent counsel during patent prosecution. Both the outside patent counsel and TTO staff would likely need the faculty inventor to be engaged and to provide his or her input.

Further, the scheduling does not consider downstream of the TTO job tasks such as the amount of time that an industry partner takes to review a draft of a licensing agreement or patent prosecution documentation when there is co-inventorship between the university's faculty and the industry partner's employees. Considering all estimated completion times and deadlines for job tasks by all parties in the university technology transfer supply chain will make the job scheduling tool more comprehensive and overcome this limitation. A further limitation was that a hypothetical set of technology transfer job tasks was used in this study rather than having TTO specialists make use of the proposed job scheduling tool in real time with actual job tasks.

\section{Directions for Future Research}

Future research should include further experimentation in actual university technology transfer offices using the job tasks that their specialists need to schedule in real time. Moreover, there are opportunities to conduct future research which considers the entire 
university technology commercialization supply chain network. The upstream and downstream scheduling of patent counsel tasks, gathering inventor input in patenting activities, and scheduling industry licensing partners' involvement would make for a more robust and realistic job scheduling tool. A university should be targeted as a case study for the use of this job scheduling tool.

\section{Conclusion}

Advanced supply chain planning addresses decisions about the coordination, design and short term scheduling of supply chain processes (Fleischmann, 2003). Currently, there is no scholarly literature referencing the use of job scheduling tools in university technology transfer. The AUTM Technology Transfer Practice Manual for technology transfer professionals does not reference such use either. There are manual chapters that discuss docketing systems with manual file management and scanned files (Sadowski, 2006); database management (Cleary, 2006); and electronic records management systems that include auto reminders for deadlines and decision support (Argawal, 2006). However, none of these TTO management tool publications mention job scheduling for TTO staff tasks. So, the use would require advocacy, and the marketing of success stories. Job scheduling is crucial because it has the potential for improving staff accountability and trust between the TTO staff and faculty. However, TTO staff that value their academic freedom and autonomy may resist the use of job scheduling tools.

In order to alleviate the problem with job task delays in the university technology transfer process, job scheduling techniques were explored. It was discovered through experimentation that simulation annealing is an advanced optimization tool that is well suited for university technology transfer job scheduling. In comparison to a commercially available Excel Solver scheduling tool, the meta-heuristic simulated annealing program converged to an optimal solution that satisfied the constraints. The Excel Solver personnel scheduling tool by Slaver did not find a feasible solution and did not schedule all of the jobs to all three TTO staff persons. The use of simulated annealing for job scheduling statistically guarantees finding an optimal solution (Ingber, 1993). The job scheduling tool experimentation illustrates how advanced optimization can be used to schedule TTO staff job tasks in a very quick and simple manner.

Journal of Applied Management, Vol. 20, 2019 


\section{References}

Argawal, S. J. (2006). Electronic management and tracking (3rd ed., Vol. 2). In AUTM technology transfer practice manual. Chicago: AUTM.

Bahouth, S. (2014). Taxonomy of shop scheduling. Available at SSRN 2447152.

Baldini, N. (2008). Negative effects of university patenting: Myths and grounded evidence. Scientometrics, 75, 289-311.

Bercovitz, J., \& Feldman, M. (2003, June). Technology transfer and the academic department: Who participates and why? In DRUID summer conference on Creating, Sharing and Transferring Knowledge: The Role of Geography (Vol. 15, pp. 12-14). Copenhagen.

Bozeman, B., \& Coker, K. (1992). Assessing the effectiveness of technology transfer from US government R\&D laboratories: the impact of market orientation. Technovation, 12 (4), 239255.

Bozeman, B., Rimes, H., \& Youtie, J. (2015). The evolving stateof-the-art in technology transfer research: Revisiting the contingent effectiveness model. Research Policy, 44 (1), 34 49.

Cao, Y., Zhao, L., \& Chen, R. (2009). Institutional structure and incentives of technology transfer: Some new evidence from Chinese universities. Journal of technology management in China, 4 (1), 67-84.

Cleary, C.\& Bohlman, M. (2006). Data management AUTM technology transfer practice manual (3rd ed., Vol. 2, pp. 110). Chicago, AUTM.

Colwell, K.A. (2002, August). Testing the effectiveness of organizational practices in university technology transfer programs. In Academy of Management Proceedings (Vol. 2002, No. 1, pp. A1-A6). Briarcliff Manor, NY: Academy of Management.

Feldman, R. \& Nelson, K. (2008). Open source, open access, and open transfer: Market approaches to research bottlenecks. Northwestern Journal of Technology and Intellectual Property, 7, 14.

Fleischmann, B., \& Meyr, H. (2003). Planning hierarchy, modelilng and advanced planning systems. I n S. C. Graves \& A. G. deKok (Eds.), Supply chain management, design, coordination and operation (Vol. 11, pp. 455-523). Amsterdam, Netherlands: Elsevier Science.

Forrester, J. W. (1961). Industrial dynamics. Cambridge, MA: Springer. 
Forrester, J. W. (1993). System dynamics and the lessons of 35 years. In K. B. DeGreene (Ed.), A systems-based approach to policymaking (pp. 199-240). Boston, MA: Springer.

Goffe, W. L., Ferrier, G. D., \& Rogers, J. (1994). Global optimization of statistical functions with simulated annealing. Journal of Econometrics, 60 (1-2), 65-99.

Hamilton, C. \& Schumann, D. (2016), Love and hate in university technology transfer: examining faculty and staff conflicts and ethical issues. In The contribution of love, and hate, to organizational ethics (Research in Ethical Issues in Organizations (Vol. 16, pp., 95-122), Bingley, UK: Emerald Group Publishing.

Hamilton, C. (2017a). HBCU technology transfer supply chain networks' sustainability: Budget resource planning tool development. In Proceedings of the 35th International Annual Conference of the American Society for Engineering Management: Reimagining Systems Engineering and Management, Huntsville, AL.

Hamilton, C. (2017b). Emerging research institutions' technology transfer supply chain networks' sustainability: Budget resource planning tool development. IEEE Engineering Management Review, 45 (4), 39-52.

HBCU innovation and entrepreneurship collaborative. (2014). Retrieved May 7, 2015, from http://www.aplu.org/projectsand-initiatives/access-and-diversity/hbcu-innovationcommercialization-and-entrepreneurship/

Hedjazi, D. (2015). Scheduling a maintenance activity under skills constraints to minimize total weighted tardiness and late tasks. International Journal of Industrial Engineering Computations, 6 (2), 135-144.

Ingber, L. (1993). Simulated annealing: Practice versus theory. Mathematical and computer modelling, 18 (11), 2957.

Kanet, J. J., \& Davis, J. S. (1991). Production planning for quick response. Clemson University, Clemson Apparel Research. Alexandria, VA: US Defense Logistics Agency.

Kenney, M., \& Patton, D. (2009). Reconsidering the Bayh-Dole Act and the current university invention ownership model. Research Policy, 38 (9), 1407-1422.

Ketchen Jr, D. J., Rebarick, W., Hult, G. T. M., \& Meyer, D. (2008). Best value supply chains: A key competitive weapon for the 21st century. Business Horizons, 51 (3), 235-243.

Kurbel, K. (2016). Enterprise resource planning and supply chain management: Functions, business processes and software for 
manufacturing companies. Berlin/Heidelberg, Germany: Springer-Verlag.

Markman, G. D., Gianiodis, P. T., Phan, P. H., \& Balkin, D. B. (2005). Innovation speed: Transferring university technology to market. Research Policy, 34 (7), 1058-1075.

Ohsaki, M. (2016). Optimization of finite dimensional structures. Boca Raton, FL: CRC Press Taylor \& Francis Group.

Sadowski, D. R. (2006). Avoiding the avalanche: Records management techniques for improving workflow in technology transfer offices. In AUTM technology transfer practice manual (3rd ed., Vol. 2, pp. 1-11). Chicago, IL: Association of University Technology Managers.

Schmidt, W. \& Uydess, I. (2011). Keys to executing a successful technology transfer. Pharmaceutical Technology, 35 (2), pp. $1-4$.

Spivey, W. A., Munson, J. M., Flannery, W. T., \& Tsai, F. S. (2009). Improve tech transfer with this alliance scorecard. Research-Technology Management, 52 (1), 10-18.

Straver, E. \& Fylstra, D. H. (2001). Six solver workbooks: Human resources and scheduling examples. Retrieved January 21, 2016, from https://www.solver.com/optimization-solutionshuman-resources-and-scheduling-examples

Swamidass, P. M., \& Vulasa, V. (2009). Why university inventions rarely produce income? Bottlenecks in university technology transfer. Journal of technology transfer, 34 (4), 343-363.

Tahvanainen, A. \& Hermans, R. (2008). "Value Creation in the Interface of Industry and Academy - A Case Study of Intellectual Capital of Technology Transfer Offices at US Universities," Discussion Papers 1148, The Research Institute of the Finnish Economy. Retrieved November 24, 2019, from https://ideas.repec.org/p/rif/dpaper/1148.html

Totten, G. E. (2006). Steel heat treatment handbook (2 Volume Set, 2nd ed.). Boca Raton, FL: CRC Press Taylor \& Francis Group.

Zapfel, G., Braune, R., \& Bogl, M. (2010). Metaheuristic search concepts: A tutorial with applications to production and logistics. Berlin/Heidelberg, Germany: Springer-Verlag.

\section{Biographical Note}

Clovia Hamilton earned a $\mathrm{PhD}$ in Industrial \& Systems Engineering with a concentration in Engineering Management from the University of Tennessee Knoxville. She also has a JD; a Master of Laws (LLM) in Intellectual Property Law from the University of Illinois at UrbanaChampaign; and MBA. Her published research is focused on 
university technology commercialization operations. Dr. Hamilton is a former USPTO patent examiner and a registered patent attorney. (hamiltoncl@winthrop.edu)

Accepted after two revisions: June 15, 2019

\section{Appendix}

Figure 1

\section{University Technology Transfer Process Flow}

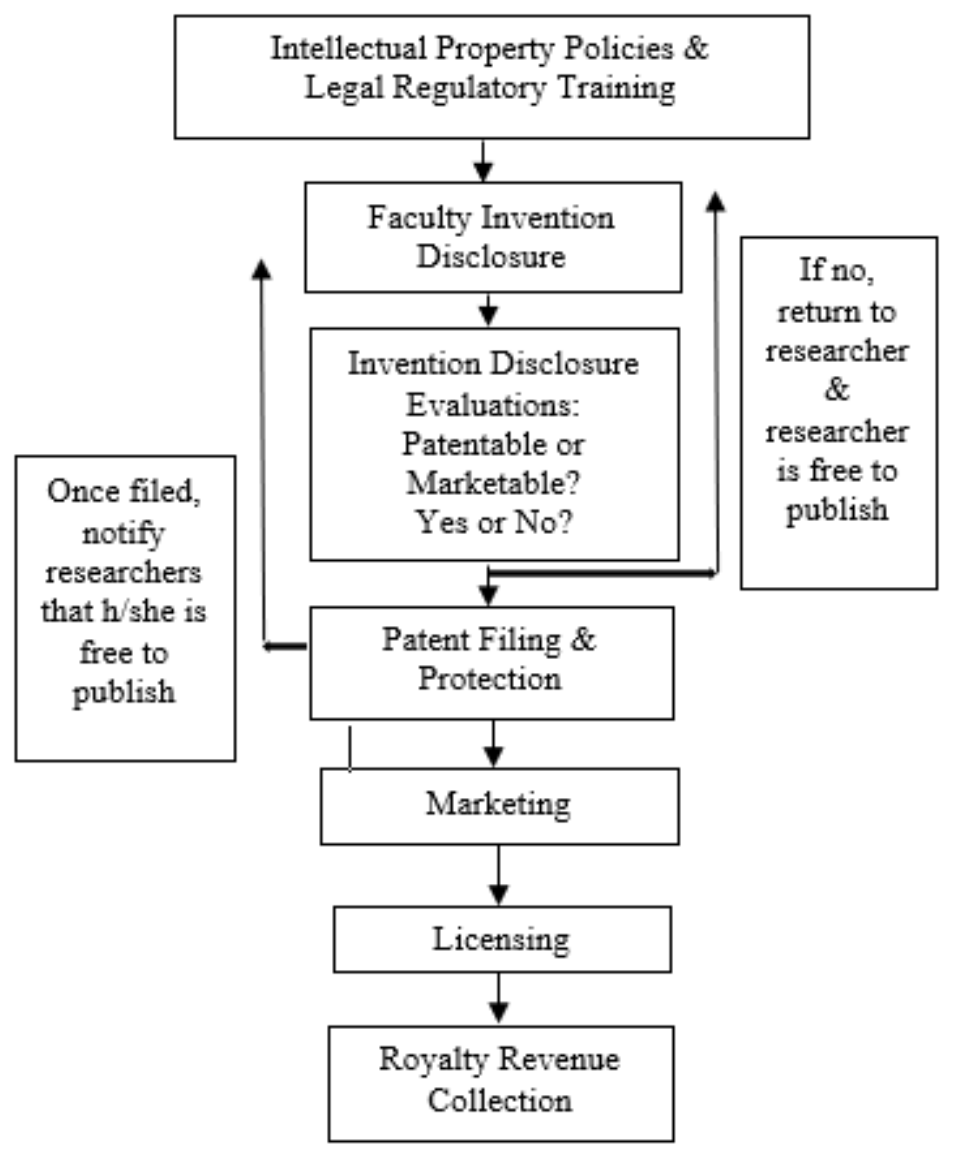

Journal of Applied Management, Vol. 20, 2019 
Figure 2

\section{Simulated annealing control flow algorithm}

\begin{tabular}{|c|c|c|c|c|}
\hline \multicolumn{5}{|c|}{ Generate initial solution } \\
\hline \multicolumn{5}{|c|}{ Assign initial temperature } \\
\hline \multicolumn{5}{|c|}{ Assign number of iterations at each temperature level } \\
\hline \multicolumn{5}{|c|}{ While termination criteria are not satisfied do } \\
\hline & for & \multicolumn{3}{|c|}{$\mathrm{i}=1$ to iter $\mathbf{d o}$} \\
\hline & & \multicolumn{3}{|c|}{$\begin{array}{l}\text { Generate new neighbor s' by randomly sampling the set of } \\
\text { possible job tasks; }\end{array}$} \\
\hline & & \multicolumn{3}{|c|}{ Compute $\Delta \mathrm{h}=\mathrm{h}$ state $-\mathrm{h}$ current; } \\
\hline & & \multicolumn{3}{|l|}{ if } \\
\hline & & & \multicolumn{2}{|c|}{$\begin{array}{l}\text { Switch over to solution } x^{\prime} \text { (current solution } \mathrm{s} \text { is } \\
\text { replaced by s'); }\end{array}$} \\
\hline & & \multicolumn{3}{|c|}{ else } \\
\hline & & & \multicolumn{2}{|c|}{ Generate random number $\mathrm{r}$ in $\in[0,1]$; } \\
\hline & & & if & $\mathrm{r} \leq \exp \left(-\Delta \mathrm{h} / \mathrm{T}_{\mathrm{k}}\right)$ then \\
\hline & & & & $\begin{array}{l}\text { Switch over to solution s'(current solution } s \text { is } \\
\text { replaced by s'); }\end{array}$ \\
\hline & & & end & \\
\hline & & \multicolumn{3}{|c|}{ end } \\
\hline & end & & & \\
\hline & \multicolumn{4}{|c|}{ Update the best solution if appropriate; } \\
\hline & \multicolumn{4}{|c|}{ Set $\mathrm{k}<-\mathrm{k}+1$} \\
\hline & \multicolumn{4}{|c|}{ Set 1 update temperature value $T_{k}$ for the next level $\mathrm{k}$} \\
\hline \multicolumn{5}{|c|}{ ( } \\
\hline return & \multicolumn{4}{|c|}{ best solution. } \\
\hline
\end{tabular}




\section{Table 1}

Job Scheduling Algorithm Terminology and Variables

\begin{tabular}{|c|c|}
\hline Domain $\mathrm{x}$ & $\begin{array}{l}\mathrm{X} \text { axis which is the collection of all possible } \\
\text { combinations of job assignments that have an outcome }\end{array}$ \\
\hline $\mathrm{h}(\mathrm{x})$ & Y axis \\
\hline Local maximum & $\begin{array}{l}\text { A given range for the location of the maximum value of } \\
\text { the function }\end{array}$ \\
\hline Global maximum & $\begin{array}{l}\text { The maximum located in the entire domain of the } \\
\text { function }\end{array}$ \\
\hline Temperature & $\begin{array}{l}\text { In the simulation of the annealing process, the } \\
\text { temperature restricts the algorithm from jumping around } \\
\text { anywhere. It is a measure of how much worse a state can } \\
\text { be accepted. The temperature gets cooled down to make } \\
\text { it less and less likely for the worse state to get selected. }\end{array}$ \\
\hline Best solution & Lowest value for the objective function \\
\hline Current solution & Current state of the objective function value \\
\hline \multicolumn{2}{|l|}{ Variables } \\
\hline dur & Vector with durations \\
\hline ndur & Length of duration vector \\
\hline pers & Vector of TTO staff persons \\
\hline npers & No. of persons in the TTO staff \\
\hline dur.per.pers & Total duration for each person \\
\hline disturb & $\begin{array}{l}\text { This is the delta } \mathrm{h} \text { which is the amount of disturbance } \\
\text { which is a measure of likeliness that a worse solution is } \\
\text { selected }\end{array}$ \\
\hline rho, $\rho$ & $\begin{array}{l}\text { \% chance allowed for } \mathrm{h}(\mathrm{x}) \text { to be in its worse state }=\exp \\
\text { (delta h/temp) } \\
\text { Thus, temp } * \log (\text { rho })=\text { delta } \mathrm{h} \\
\text { The formula for rho includes a temperature } \\
\text { This is done with the runif command in } \mathrm{R} \text { programming } \\
\text { since it takes a random probability between } 0 \text { and } 1 \text { and } \\
\text { multiples it with temp to get disturb, a value which is } \\
\text { always between } 1 \text { and } 0 \text {. } \\
\text { Runif is always smaller than } 1 . \text { So, its logarithm is always } \\
\text { smaller than zero. }\end{array}$ \\
\hline iter & No. of iterations; used $1 \times 10^{\wedge} 4=100,000 ;$ began at 1 \\
\hline scale & Scaling factor for the probability $=0.8$ \\
\hline unchanged & Begin at zero \\
\hline max.unchanged & $\begin{array}{l}\text { Maximum number of iterations where best solution can } \\
\text { remain }\end{array}$ \\
\hline state & Current state begins with best variable's value \\
\hline h_state & Begins with h_best state \\
\hline best & The initial best solution of randomly assigned jobs \\
\hline hbest & Vector to sample from \\
\hline h_best & $\begin{array}{l}\text { Calculated with the objective function using the durations } \\
\text { computed from the variables } d u r \text { and best }\end{array}$ \\
\hline h_diff & (h_state - h_current) $*$ scale \\
\hline temp & $\begin{array}{l}\text { Begins with value } 1 \text {. The temperature moves closer and } \\
\text { closer to zero in the plot of disturbance values. The more } \\
\text { iterations, the closer it moves to zero. }\end{array}$ \\
\hline jobs & Data frame of job and time information \\
\hline
\end{tabular}

Journal of Applied Management, Vol. 20, 2019 


\begin{tabular}{|l|l|}
\hline job & Vector of job task names \\
\hline Time & Vector of job task times \\
\hline
\end{tabular}

Table 2

Hypothetical University Technology Transfer Job Tasks

\begin{tabular}{|c|c|c|c|}
\hline Total of 11 jobs & $\begin{array}{c}\text { Estimated time to } \\
\text { complete } \\
\text { (hrs. each) }\end{array}$ & $\begin{array}{c}\text { Total estimated } \\
\text { required time } \\
\text { (hrs.) }\end{array}$ & $\begin{array}{c}\text { Deadline } \\
\text { Day in the } \\
\text { month }\end{array}$ \\
\hline $\begin{array}{c}\text { Complete 3 separate } \\
\text { training seminars in } \\
\text { 3 different colleges }\end{array}$ & 4 & 12 & 1 \\
\hline $\begin{array}{c}\text { Evaluate 3 separate } \\
\text { invention } \\
\text { disclosures }\end{array}$ & 2 & 6 & 4 \\
\hline $\begin{array}{c}\text { Review patent } \\
\text { prosecution }\end{array}$ & & & 3 \\
$\begin{array}{c}\text { documentation from } \\
\text { outside patent } \\
\text { counsel regarding 2 } \\
\text { different inventions }\end{array}$ & 1 & 2 & 4 \\
\hline $\begin{array}{c}\text { Create marketing } \\
\text { plans for 3 different } \\
\text { patented inventions }\end{array}$ & & & 2 \\
\hline & 2 & 6 & 4 \\
\hline
\end{tabular}


Figure 3

h Value Sequence Plots

$h$ value sequence

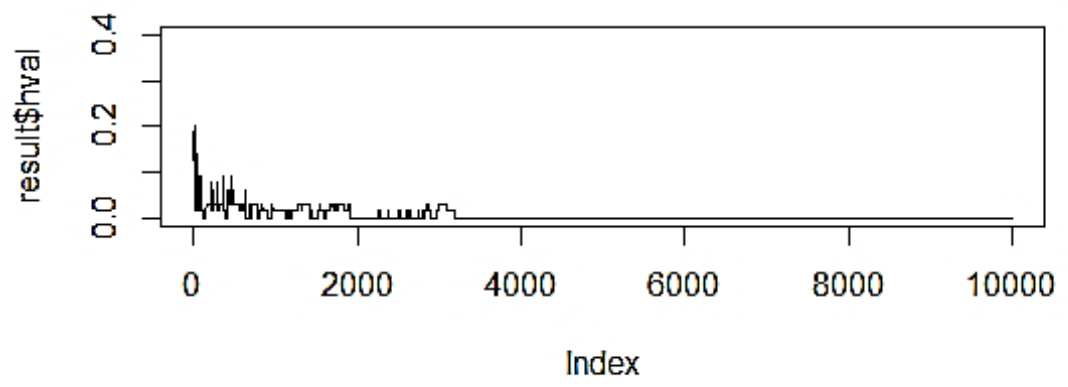

best $h$ value sequence

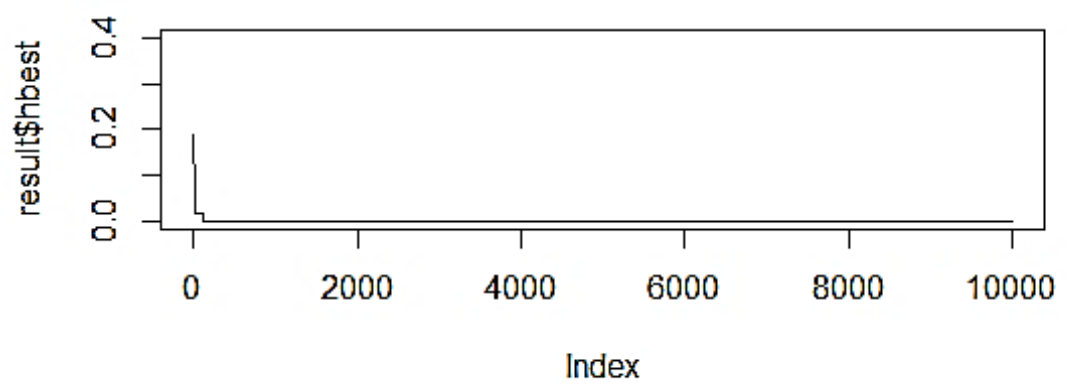

Figure 4

University Technology Transfer Job Scheduling Simulation Convergence

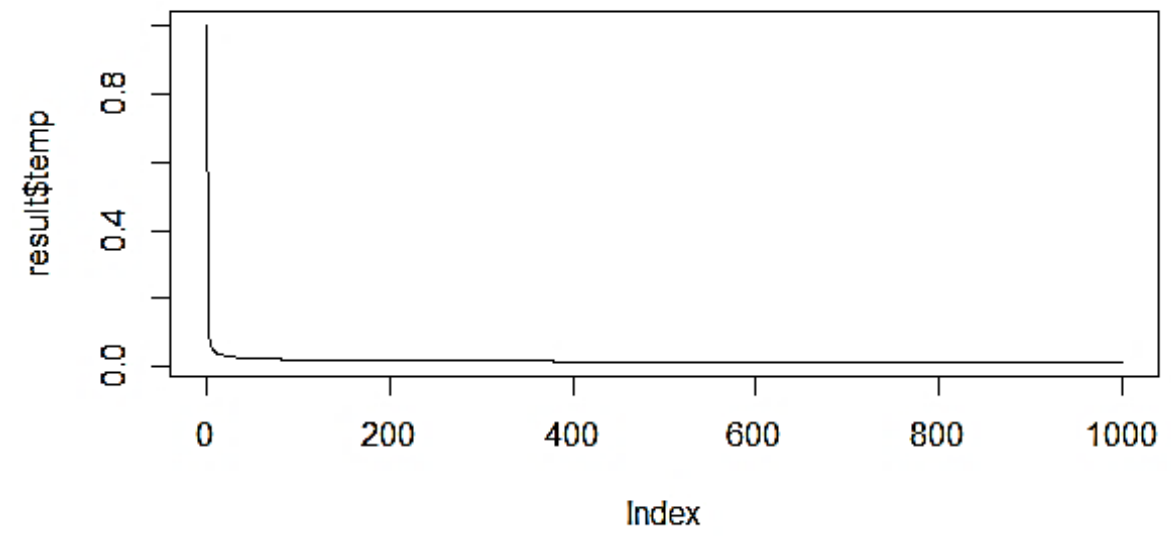

Journal of Applied Management, Vol. 20, 2019 
C. Hamilton

Figure 5

Decrease of Disturbance

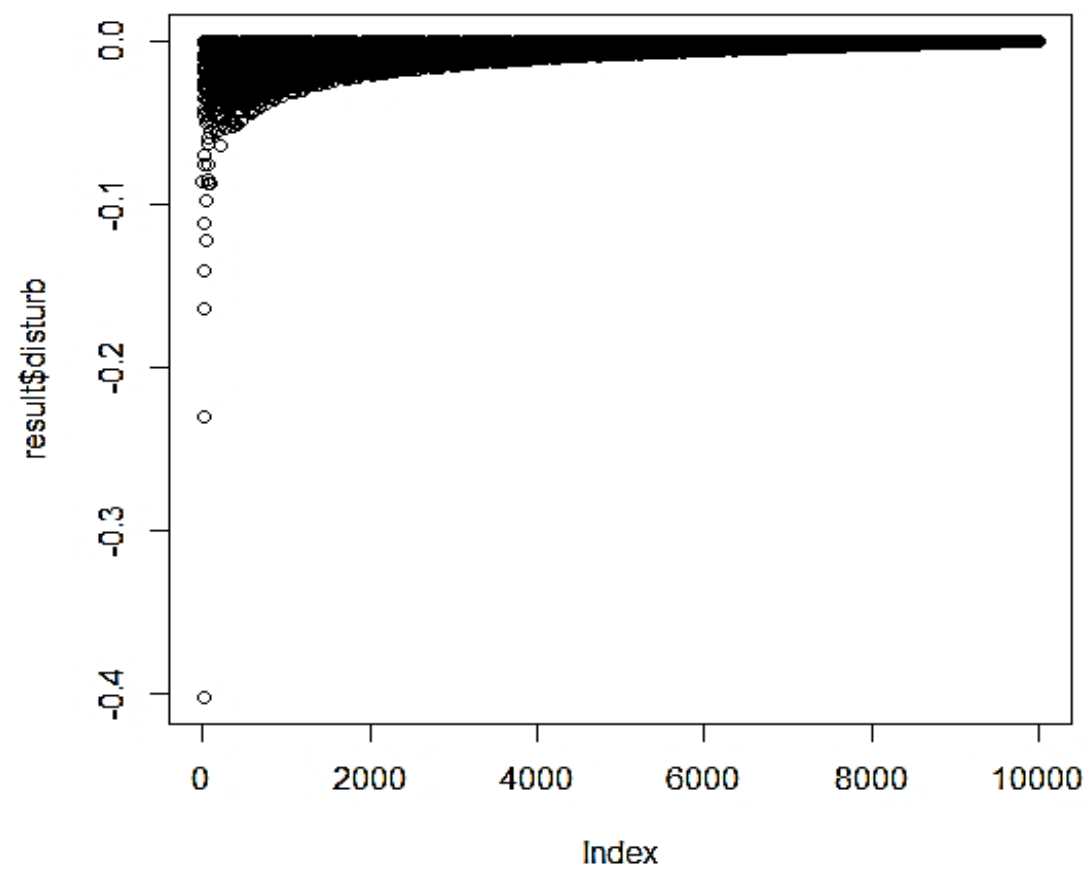

Figure 6

Gantt chart solution to University Technology Transfer Job Scheduling using Simulated Annealing

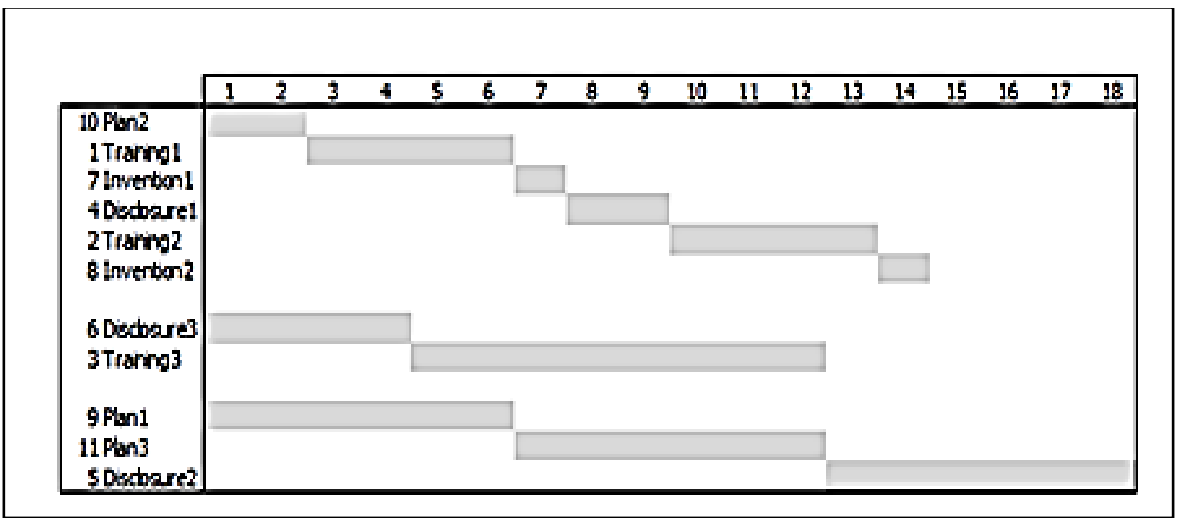

Journal of Applied Management, Vol. 20, 2019 